Check for updates

Cite this: Phys. Chem. Chem. Phys., $2021,23,8403$

Received 29th June 2020

Accepted 18th March 2021

DOI: $10.1039 / \mathrm{d0cp03481a}$

rsc.li/pccp

\title{
Simultaneous sulfidation of Mo and Co oxides supported on Au(111) $\dagger$
}

\author{
M. K. Prabhu (D) and I. M. N. Groot (D) *
}

\begin{abstract}
Here we present the results of a study carried out to investigate the simultaneous sulfidation of Co and Mo oxide nanoparticles on Au(111) as a synthesis strategy to prepare a model catalyst for hydrodesulfurization (HDS). We make use of scanning tunneling microscopy and X-ray photoelectron spectroscopy to track the changes in morphology and chemistry during the synthesis of a mixed Mo and Co oxide precursor and the sulfidation thereafter, to the respective sulfides. We investigated the effects of temperature and the duration of sulfidation on the completeness of the sulfidation process. Our study shows that the formation of $\mathrm{MoS}_{2}$ with the CoMoS edge (the desired model catalyst) is not affected by the time or the temperature of sulfidation. However, the yield of the Co-promoted $\mathrm{MoS}_{2}$ slabs is limited by the formation of large clusters due to the spreading of Mo and Co oxide phases upon sulfidation. Complete sulfidation of the mixed oxide precursor to Co-promoted $\mathrm{MoS}_{2}$ can be accelerated by increasing the sulfidation temperature to $730 \mathrm{~K}$ due to the thermally activated nature of Mo oxide sulfidation. Thus, we demonstrate that using a mixed Mo and Co oxide precursor as a starting point for the Co-promoted $\mathrm{MoS}_{2}$ phase for fundamental catalytic studies is a viable strategy.
\end{abstract}

\section{Introduction}

Graphite-like layered materials such as the transition metal dichalcogenides (TMDC) have garnered a lot of attention from the scientific community over the last decade. ${ }^{1}$ The atomic structure of TMDCs consists of a layer of metal atoms sandwiched between two layers of chalcogen (S, Se or Te) atoms resulting in an $\mathrm{MX}_{2}$-type stoichiometry. In the bulk, such molecular layers are held together by van der Waals forces. Like graphene from graphite, single-layer (SL) TMDCs can be exfoliated from the bulk. ${ }^{2}$ The most widely studied among SL TMDCs include $\mathrm{MoS}_{2}$ and $\mathrm{WS}_{2} \cdot{ }^{3}$ Single-layer $\mathrm{MoS}_{2}$ has a direct band gap unlike its bulk counterpart, and has found applications in a variety of fields such as electronics, ${ }^{4}$ biochemistry, ${ }^{5}$ efficient energy harvesting and storage ${ }^{6,7}$ and catalysis. ${ }^{8}$

In many of these applications, nanosheets of SL $\mathrm{MoS}_{2}$ deposited on substrates like $\mathrm{Au}(111),{ }^{9,10}$ highly-oriented pyrolytic graphite ${ }^{11}$ and $\mathrm{TiO}_{2}(110)^{12-14}$ are employed. Typically, these nanosheets are doped with foreign metal atoms such as $\mathrm{Co}$ or $\mathrm{Ni}$ to enhance their properties, for instance, the catalytic activity. Such doped SL MoS 2 slabs have been widely used in

Gorlaeus Laboratories, Leiden Institute of Chemistry, Leiden University,

Einsteinweg 55, 2333 CC, Leiden, The Netherlands.

E-mail: i.m.n.groot@lic.leidenuniv.nl

$\dagger$ Electronic supplementary information (ESI) available. See DOI: 10.1039/ d0cp03481a catalytic applications such as hydrodesulfurization (HDS), ${ }^{15,16}$ $\mathrm{CO}_{2}$ hydrogenation ${ }^{17}$ and in fuel cell electrodes. ${ }^{18,19}$ The SL Coor Ni-promoted $\mathrm{MoS}_{2}$ for these applications is usually grown by wet chemical methods ${ }^{16}$ chemical vapor deposition (CVD), ${ }^{20}$ thermal decomposition ${ }^{21}$ or physical vapor deposition (PVD). ${ }^{22,23}$ PVD in particular is useful for producing highquality promoted SL $\mathrm{MoS}_{2}$ slabs and thus, has been the choice process for synthesizing the Co-promoted $\mathrm{MoS}_{2}$ for fundamental research. The PVD method makes use of a mixture of metallic Co and Mo nanoparticles as a precursor. The metal nanoparticles, being highly reactive, readily form the promoted $\mathrm{MoS}_{2}$ slabs in the presence of a chalcogen-containing reactive gas such as $\mathrm{H}_{2} \mathrm{~S}^{23}$ In many of the industrially relevant synthesis strategies such as the wet impregnation method, however, the precursor to form the promoted $\mathrm{MoS}_{2}$ nanoparticles, for instance, Co-promoted $\mathrm{MoS}_{2}$, is a mixture of the respective oxides: Mo oxide and Co oxide. As an example, the HDS catalyst containing Co-promoted $\mathrm{MoS}_{2}$ can be formed by sulfiding a mixture of $\mathrm{MoO}_{3}$ and $\mathrm{Co}_{3} \mathrm{O}_{4}$ nanoparticles. ${ }^{24,25}$ The transformation of the metal oxide nanoparticles to metal sulfide can show a more complex behavior than the respective metal nanoparticles because of the reducibility of the oxides and the metal oxidation-state-dependent susceptibility towards sulfidation. ${ }^{26-28}$ From the point of view of real catalysts used in the industry, it is important to understand the process of sulfiding a mixture of Mo and Co oxide nanoparticles in order to control the morphology of the Co-promoted $\mathrm{MoS}_{2}$ slabs. 
Molybdenum oxides have been studied in the past on supports such as $\mathrm{Au}(111),{ }^{28-32}$ highly-oriented pyrolytic graphite (HOPG), ${ }^{33} \mathrm{NiAl}^{34}$ and $\mathrm{TiO}_{2}(110){ }^{35}$ The typical preparation methods used in these studies involve direct sublimation of $\mathrm{MoO}_{3}$ powder, oxidation of Mo clusters, or CVD-like processes involving carbonyl complexes of Mo with $\mathrm{NO}_{2}$ as the oxidizing agent. Additionally, prior work carried out in our group ${ }^{34}$ demonstrates a method of directly evaporating Mo oxides from a source containing Mo metal. Co oxide has been synthesized by oxidizing Co nanoclusters on substrates like $\mathrm{Ag}(111),{ }^{36} \mathrm{Pt}(111)^{37,38}$ and $\mathrm{Au}(111) \cdot{ }^{39-44}$ This method produces pristine Co oxide slabs containing $\mathrm{Co}^{2+}$ and $\mathrm{Co}^{3+}$ depending on the oxygen background pressure used; higher $\mathrm{O}_{2}$ pressures resulting in a higher oxidation state of the metal atom. The Co oxide slabs thus synthesized are known to form layered $\mathrm{Co}-\mathrm{O}$ or O-Co-O-type structures. Additionally, the oxidation and reduction of these slabs have also been reported. ${ }^{36,42,43}$

Recently, sulfidation of $\mathrm{MoO}_{3}$ supported on $\mathrm{Au}(111)$ was studied using scanning tunneling microscopy (STM) and X-ray photoelectron spectroscopy (XPS). ${ }^{28}$ It was shown that the progressive annealing of the PVD-grown $\mathrm{MoO}_{3}$ results in the reduction of $\mathrm{Mo}^{6+}$ to lower oxidation states, thus forming substoichiometric Mo oxides. Extensive sulfidation with $\mathrm{H}_{2} \mathrm{~S}$ was found to be necessary to form SL $\mathrm{MoS}_{2}$ slabs as the oxide phase readily undergoes reduction and oxygen-sulfur exchange to form a stable oxysulfide phase, thereby hindering the complete sulfidation. It was observed that the sulfidation to $\mathrm{MoS}_{2}$ was most efficient when Mo remained predominantly in its highest oxidation state, namely, $\mathrm{Mo}^{6+}$. The sulfidation of aforementioned cobalt oxide slabs, on the other hand, has not been studied so far. The sulfidation to $\mathrm{Co}_{9} \mathrm{~S}_{8}$ and $\mathrm{Co}_{3} \mathrm{~S}_{4}$ have been observed in sorbents containing $\mathrm{Co}_{3} \mathrm{O}_{4}$ supported on $\mathrm{TiO}_{2} \cdot{ }^{45}$ However, fundamental studies involving sulfidation of cobalt oxides have predominantly been performed in conjunction with Mo oxide nanoparticles as a method to synthesize catalysts for HDS. ${ }^{21,46-48}$ Furthermore, model catalyst experiments on $\mathrm{MoS}_{2}$ in the last decade have shown that STM is a very powerful technique for directly observing the incorporation of Co atoms in the $\mathrm{MoS}_{2}$ phase. $^{22,23,49}$

In this study, we aim to gain insights into the sulfidation of a mixture of Co and Mo oxide precursors. Particularly, we investigate the formation of the Co-promoted $\mathrm{MoS}_{2}$ phase. In order to do this, we first synthesize a precursor containing nanoparticles of Mo and Co oxides on an Au(111) substrate. Thereafter, the mixed oxide precursor is sulfided using hydrogen sulfide at $650 \mathrm{~K}$ for 25 to $90 \mathrm{~min}$ and at $730 \mathrm{~K}$ for $25 \mathrm{~min}$ in order to investigate the effects of time and temperature on the completeness of the sulfidation process and the formation of the Co-promoted $\mathrm{MoS}_{2}$ phase. Using a combination of STM and XPS, we observe the formation of large clusters containing the $2 \mathrm{D}$ $\mathrm{CoS}_{2}$ and the Co-promoted $\mathrm{MoS}_{2}$ phases as well as small singlelayer (SL) Co-promoted $\mathrm{MoS}_{2}$ slabs. The results presented in this study show that by using a mixed oxide precursor as a starting point, the Co-promoted $\mathrm{MoS}_{2}$ phase can be synthesized, albeit with a low yield due to the kinetically-hindered sulfidation of Mo oxide.

\section{Experimental methods}

\section{Substrate cleaning}

The experiments described in this paper were carried out in the ReactorSTM setup. ${ }^{50}$ The $\mathrm{Au}(111)$ single crystal was purchased from Surface Preparation Laboratory and cleaned with cycles of sputtering and annealing. Sputter cleaning with $\mathrm{Ar}^{+}$was performed under an argon atmosphere of $1 \times 10^{-6} \mathrm{mbar}$ and with an ion energy of $1.5 \mathrm{keV}$. The $\mathrm{Au}(111)$ crystal was then annealed to $850 \mathrm{~K}$ using radiative heating for $45 \mathrm{~min}$ to obtain atomically flat gold terraces. The cleanliness was checked with XPS and STM until impurities were below the detection limits.

\section{Evaporation of Co and Mo oxides}

Evaporation of the Mo and Co oxides was performed using an Oxford EGCO4 e-beam evaporator. In the case of Mo oxide, the Mo rod was heated to $\sim 1100 \mathrm{~K}$ in an oxygen atmosphere of $1 \times 10^{-5}$ mbar. At this temperature, the vapor pressure of metallic Mo is negligible. However, the $\mathrm{Mo}^{6+}$ oxide formed on the Mo rod sublimes and deposits onto the sample held at $300 \mathrm{~K}$. By maintaining the $\mathrm{O}_{2}$ background pressure low, formation of $\mathrm{Mo}^{6+}$ on the rod can be controlled and therefore, we can suppress the evaporation of Mo oxide polymers and ensure that small nanoparticles of Mo oxide are formed. The sample was then annealed to $500 \mathrm{~K}$ for $20 \mathrm{~min}$, while maintaining the background oxygen pressure. A doser was used to increase the local $\mathrm{O}_{2}$ pressure near the sample $\left(>10^{-4} \mathrm{mbar}\right)$ to suppress the reduction of Mo oxides to lower oxidation states during the annealing step. Subsequently, the sample was cooled to $300 \mathrm{~K}$ under the same $\mathrm{O}_{2}$-rich atmosphere.

Cobalt oxide was grown by depositing metallic cobalt at $300 \mathrm{~K}$ in a molecular oxygen atmosphere of $1 \times 10^{-6} \mathrm{mbar}$ followed by annealing at $600 \mathrm{~K}$ for 30 minutes while maintaining the oxygen background pressure. The sample was cooled to room temperature in the same oxygen atmosphere. This recipe has been adapted from literature and has been shown to grow layered cobalt oxides on $\mathrm{Au}(111) .{ }^{36,44}$

\section{Sulfidation}

Sulfidation of the mixed Mo and Co oxide samples was carried out in an $\mathrm{H}_{2} \mathrm{~S}$ atmosphere of $2.5 \times 10^{-6}$ mbar. Separate identical samples were prepared for investigating the effects of sulfidation at $650 \mathrm{~K}$ for 25 to $90 \mathrm{~min}$ and at $730 \mathrm{~K}$ for $25 \mathrm{~min}$. In this manner, we aim to gain insights into the effects of the duration and the temperature of sulfidation. All the samples were cooled after sulfidation to $473 \mathrm{~K}$ maintaining the $\mathrm{H}_{2} \mathrm{~S}$ background after which the sample was allowed to cool to $300 \mathrm{~K}$ in ultra-high vacuum (UHV).

\section{Scanning tunneling microscopy (STM)}

Scanning tunneling microscopy was performed at room temperature using the UHV mode of the ReactorSTM. Tips were prepared by cutting a polycrystalline Pt-Ir 90-10 wire purchased from Goodfellow without further processing. Constant current scans were performed using LPM video-rate scanning electronics described in detail elsewhere. ${ }^{5-52}$ Image processing was 
performed with a combination of home-developed Camera software and WSxM. ${ }^{53}$ Line-by-line background subtraction was performed for enhancing the contrast of STM images. Most common normal filtering was used to obtain a correctly connected surface in order to measure the height profiles. No other further processing was performed on the images reported in this paper.

\section{X-ray photoelectron spectroscopy (XPS)}

The XPS measurements were performed in a SPECS Phoibos system equipped with an XRM50 X-ray source set to the Al K-alpha line used along with a monochromator to excite the sample with a beam spot of $0.4 \mathrm{~mm}$ diameter at $55^{\circ}$ incidence. The acceleration voltage was set to $10 \mathrm{kV}$ and a power of $250 \mathrm{~W}$ was used for all the measurements. The HSA3500 hemispherical analyzer with a pass energy of $30 \mathrm{eV}$ was employed to analyze the photoemission. The Au $4 \mathrm{f}$ peak set to 84.0 eV was used to calibrate the XPS spectra obtained. The number of integrations was set to 20. The data thus obtained were characterized and quantified using CasaXPS and XPSPEAK41 software with relative sensitivity factors for surfaces. ${ }^{54}$ Gaussian-Lorentzian(35) curves were used for peak fitting using a Newton-Raphson algorithm after applying a Shirley background subtraction. For Mo 3d spectra, doublets with a spacing of $3.15 \mathrm{eV}$ due to the spin-orbit splitting of the Mo 3d signal were used for peak fitting each of the components arising from Mo and with a singlet for the $\mathrm{S} 2 \mathrm{~s}$ component. The parameters used for peak fitting are tabulated in Table 1. The peak positions of the components were obtained from previously reported literature work. ${ }^{28,31,55-58}$

\section{Results}

In order to prepare a mixed Mo and Co oxide precursor, we start with the growth of Co oxide slabs on $\mathrm{Au}(111)$. After the deposition of $\sim 0.05$ monolayers (ML) Co in an $\mathrm{O}_{2}$ atmosphere followed by oxidation of the Co nanoparticles at $600 \mathrm{~K}$, the $\mathrm{Au}(111)$ surface is covered with slabs of cobalt oxide (see Fig. 1a) which are 6-10 nm in size. The slabs are atomically flat and have a truncated

Table 1 XPS peak fitting parameters of the Mo $3 d$ and Co $2 p_{3 / 2}$ spectra

\begin{tabular}{|c|c|c|c|}
\hline Component for Co $2 \mathrm{p}_{3 / 2}$ & $\begin{array}{l}\text { Peak } \\
\text { position }(\mathrm{eV})\end{array}$ & $\begin{array}{l}\text { Component } \\
\text { for Mo 3d }\end{array}$ & $\begin{array}{l}\text { Peak } \\
\text { position }(\mathrm{eV})\end{array}$ \\
\hline $\mathrm{Co}^{2+}$ oxide & 780 & $\mathrm{Mo}^{6+}$ oxide & $233.1^{a}$ \\
\hline $\mathrm{Co}^{2+}$ oxide satellite 1 & 782 & $\mathrm{Mo}^{5+}$ oxide & $231.5^{a}$ \\
\hline $\mathrm{Co}^{2+}$ oxide satellite 2 & 785.4 & $\mathrm{Mo}^{4+}$ oxide & $230.6^{a}$ \\
\hline $\mathrm{Co}^{2+}$ oxide satellite 3 & 786.4 & $\mathrm{Mo}^{4+}$ sulfide & $229.2^{a}$ \\
\hline $\mathrm{Co}^{3+}$ oxide & 779.5 & Mo metal & $228.1^{a}$ \\
\hline $\mathrm{Co}^{3+}$ oxide satellite 1 & 780.8 & S $2 \mathrm{~s}$ & 226 \\
\hline $\mathrm{Co}^{3+}$ oxide satellite 2 & 782.1 & & \\
\hline $\mathrm{Co}^{3+}$ oxide satellite 3 & 785.1 & & \\
\hline $\mathrm{Co}^{3+}$ oxide satellite 4 & 789.4 & & \\
\hline Co metal & 778.2 & & \\
\hline Co metal satellite 1 & 781.2 & & \\
\hline Co metal satellite 2 & 783.2 & & \\
\hline Co sulfide & 777.6 & & \\
\hline Co sulfide satellite 1 & 780.6 & & \\
\hline Co sulfide satellite 2 & 782.6 & & \\
\hline
\end{tabular}

hexagonal shape. Most of the slabs of cobalt oxide have a measured height of $4.1 \AA$ (see Fig. 1b) while some of them have a height of $1.9 \AA$. We observed that the latter was formed mostly around the step edges of $\mathrm{Au}(111)$. Additionally, the Co oxide slabs have a diffuse hexagonal pattern (inset Fig. 1a) on their basal plane. We identify this as a moiré structure due to lattice mismatch with the underlying $\mathrm{Au}(111)$ surface. The moire structures of the cobalt oxide slabs which are $4.1 \AA$ high have a rotation of $\sim 6^{\circ}$ with respect to that of the slabs which are $1.9 \AA$ high (see ESI, $\dagger$ Fig. S1). All these observations match nicely with those of Walton et al., ${ }^{44}$ who have shown with combined STM experiments and DFT calculations that Co oxide slabs grow as a layered - $\mathrm{Co}-\mathrm{O}$ structure on $\mathrm{Au}(111)$. According to their experiments, Co oxide slabs with - $\mathrm{Co}-\mathrm{O}-\mathrm{Co}-\mathrm{O}$ structure have measured heights of $4 \AA$ on gold, while single -Co-O layer slabs have $1.7 \AA$ heights. They have, however, observed a higher density of single layer $\mathrm{Co}-\mathrm{O}$ islands contrary to our observations where the majority is $4.1 \AA$ high. This disagreement could be due to the higher amount of Co evaporated during synthesis in this study.

Mo oxide nanoparticles were grown on the sample containing Co oxide slabs supported on $\mathrm{Au}(111)$ by direct evaporation
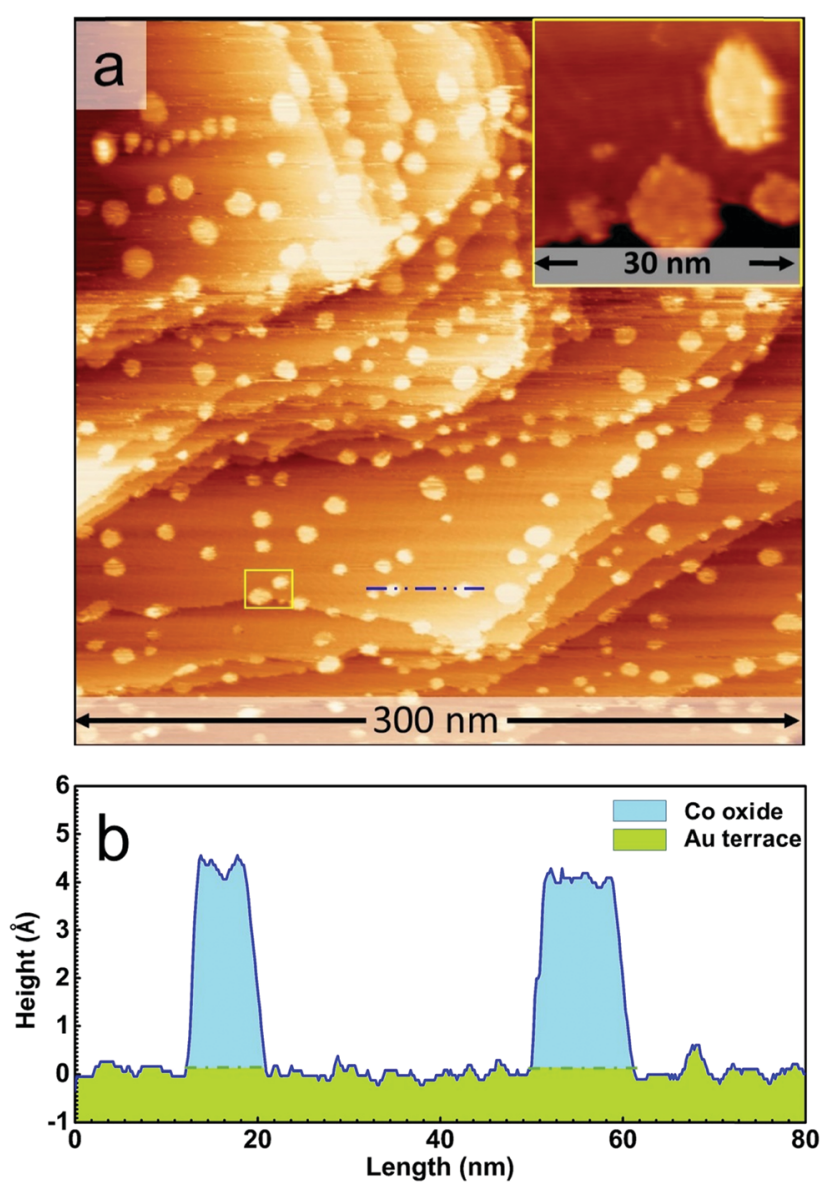

Fig. 1 (a) Large-scale STM image of Co oxide slabs on Au(111) obtained at sample voltage $=-1.6 \mathrm{~V}$, tunneling current $=150 \mathrm{pA}$. The inset shows the zoom-in of the region marked in yellow. The hexagonal moiré structure of the Co oxide slabs is clearly visible. (b) Measured height along the blue dash-double dotted line in Fig. 1a. 
detailed in the experimental methods. Mo oxide was grown until $\sim 0.05$ ML Mo was detected on the sample using XPS such that an Mo: Co ratio of 1:1 could be achieved and Mo and Co together had a total coverage of $\sim 10 \%$ of a monolayer on $\mathrm{Au}(111)$. This particular value was chosen as the typical techniques reported in literature for growing 2-3 $\mathrm{nm}$ slabs of Co-promoted $\mathrm{MoS}_{2}$ involve the use of $\sim 0.1 \mathrm{ML}$ of metallic Co and $\mathrm{Mo.}^{23}$ Our recipe resulted in the formation of Mo oxide nanoparticles with a 3D morphology (see Fig. 2a). Most of the Mo oxide particles had a measured height of 9.5-11 $\AA$ (Fig. 2b). Some Mo oxide nanoparticles were measured to have a height of 5.5-6 A. The growth mode and the morphologies of Mo oxides deposited on $\mathrm{Au}(111)$ depend on the type of precursor used, the temperature of oxidation and the oxidizing agent. ${ }^{30-32}$ Therefore, comparing the Mo oxide morphologies from our STM images with those from other Mo oxide synthesis methods on $\mathrm{Au}(111)$ reported in literature becomes difficult. To investigate the effects of Co oxide slabs on the Mo oxide morphology, we deposited Mo oxide nanoparticles directly on clean $\mathrm{Au}(111)$ (see ESI, $\dagger$ Fig. S2) in a separate experiment. We observed that the Mo oxide nanoparticles grown on clean $\mathrm{Au}(111)$ also have identical morphologies and measured STM heights, thus showing that
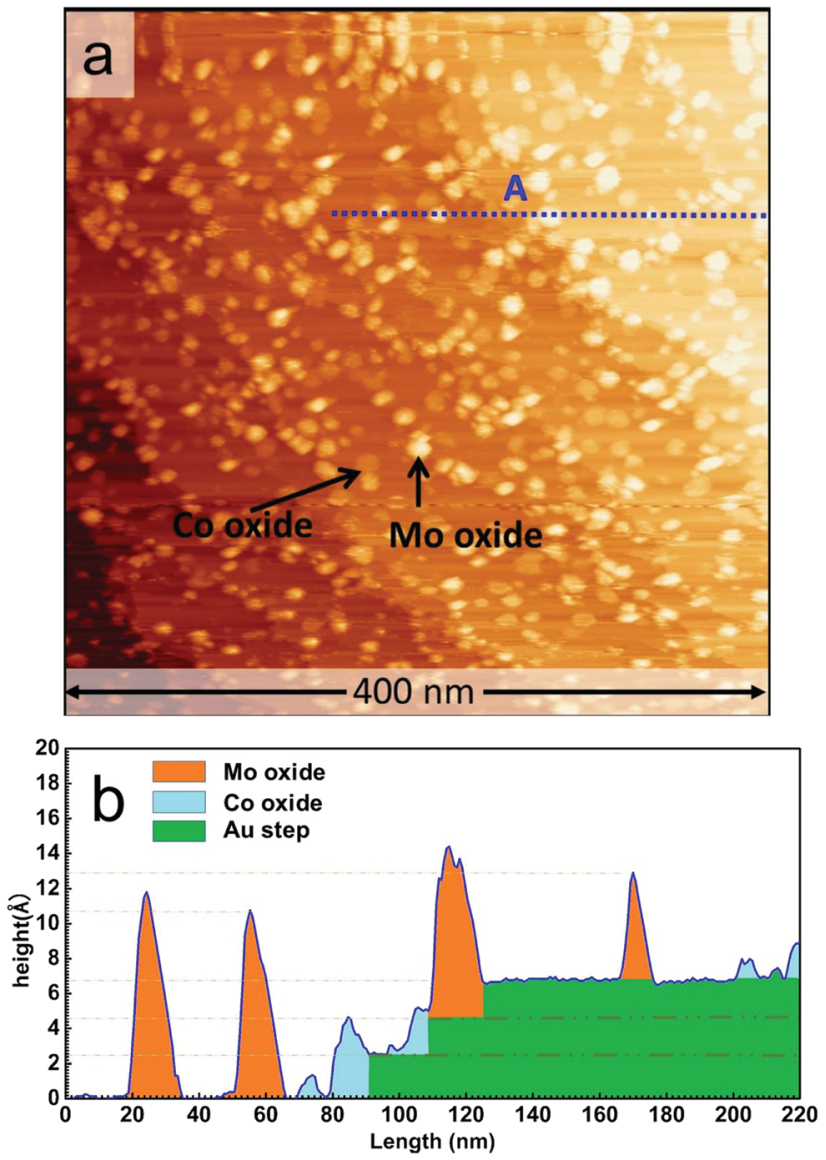

Fig. 2 (a) Large-scale STM image of Mo oxide nanoparticles on the $\mathrm{Au}(111)$ sample containing $\mathrm{Co}$ oxide slabs, sample voltage $=-1.5 \mathrm{~V}$, tunneling current $=150 \mathrm{pA}$. (b) Measured height along the blue dashed line marked $\mathrm{A}$ in Fig. 2a. the Mo oxide morphology is largely unaffected by the presence of Co oxide slabs on $\mathrm{Au}(111)$. However, we cannot rule out the possibility of some Mo oxide nanoparticles nucleating over a cobalt oxide slab. The Co oxide slabs, on the other hand, were observed to undergo changes in their morphology all of which can be attributed to the exposure to higher oxygen pressures $\left(>1 \times 10^{-5} \mathrm{mbar}\right)$ during the Mo oxide synthesis. The Co oxide slabs largely retained the truncated hexagonal shape but were observed to grow in height. We observed the presence of Co oxide slabs of $3 \AA, 4 \AA$ and $5 \AA$ heights postannealing (see ESI, $\uparrow$ Fig. S3). The previously grown single-layer Co oxide slabs of $2 \AA$ height were not observed anymore after the synthesis of Mo oxides. Fester et al. ${ }^{43}$ have observed that -Co-Otype Co oxide slabs exposed to higher oxygen pressures undergo systematic oxidation from $\mathrm{Co}^{2+}$ to $\mathrm{Co}^{3+}$ which results in the formation of -O-Co-O type slabs with measured height of $2.9 \AA$ in their experiment. We propose that the Co oxide slabs measured with heights of $3 \AA$ and $5 \AA$ are single and multilayer stacks (O-Co-O-Co-O) respectively, each containing $\mathrm{Co}^{3+}$, while those slabs with heights of $4 \AA$ are likely the unconverted double Co-O layer slabs with $\mathrm{Co}^{2+}$. It is also possible that the multilayer slabs consist of both $\mathrm{Co}^{2+}$ and $\mathrm{Co}^{3}$ layers leading to an overall mixed oxidation state of Co in the slab.

The mixed Co and Mo oxide sample thus prepared was chosen as the precursor for sulfidation using $\mathrm{H}_{2} \mathrm{~S}\left(1 \times 10^{-6} \mathrm{mbar}\right)$. Fig. 3a shows the large-scale STM image after the sulfidation at $650 \mathrm{~K}$ for $25 \mathrm{~min}$. We observed the formation of two types of structures on the $\mathrm{Au}(111)$ surface post-sulfidation: (a) large clusters of $\sim 50 \mathrm{~nm}$ size and (b) small hexagonal slabs. The large clusters consist of three phases (see Fig. 3a) with the outer two phases marked 1 and 2 in Fig. 3a being atomically flat, while the inner phase marked 3 is atomically rough. Phase 1 and 2 were often observed to encapsulate phase 3 as seen in Fig. 3a. The small hexagonal slabs are discussed later in this article.

Phase 1 has a low contrast in the STM image and has a hexagonal superstructure on its basal plane (see Fig. $3 \mathrm{~b}$ and c). This phase has a measured height of $2.4 \pm 0.2 \AA$ (Fig. 3d). We identify this phase as a SL $2 \mathrm{D}-\mathrm{CoS}_{2}$ sheet with an S-Co-S layered structure and the hexagonal superstructure being a moiré pattern due to lattice mismatch with $\mathrm{Au}(111)$. The detailed structural characterization of this phase has been carried out elsewhere. ${ }^{59}$ Phase 2 has an intermediate contrast in the STM image in comparison to Phase 1 and 3. Additionally, its basal plane shows irregular contrast variations. We identify this layer as an $\mathrm{MoS}_{2}$ slab which is not fully crystalline. These contrast variations are attributed to the presence of a large number of defects resolved further in the atom-resolved STM image in Fig. 3c. Single-layer $\mathrm{MoS}_{2}$ slabs on gold have a reported measured height of $2 \pm 0.3 \AA$ when measured at similar sample voltages. ${ }^{9}$ However, we measure a height of $4.5 \pm 0.2 \AA$ for the $\mathrm{MoS}_{2}$ slabs present in phase 2 (see Fig. 3d and e) suggesting the presence of a double layer. It is also possible that the second $\mathrm{MoS}_{2}$ layer is supported over a layer of the $2 \mathrm{D} \mathrm{CoS}$ sheet. The innermost phase marked 3, which has atomic roughness, is very likely an Mo oxysulfide phase. Reducible oxides of metals such as Mo, Ti, and Ce are known 

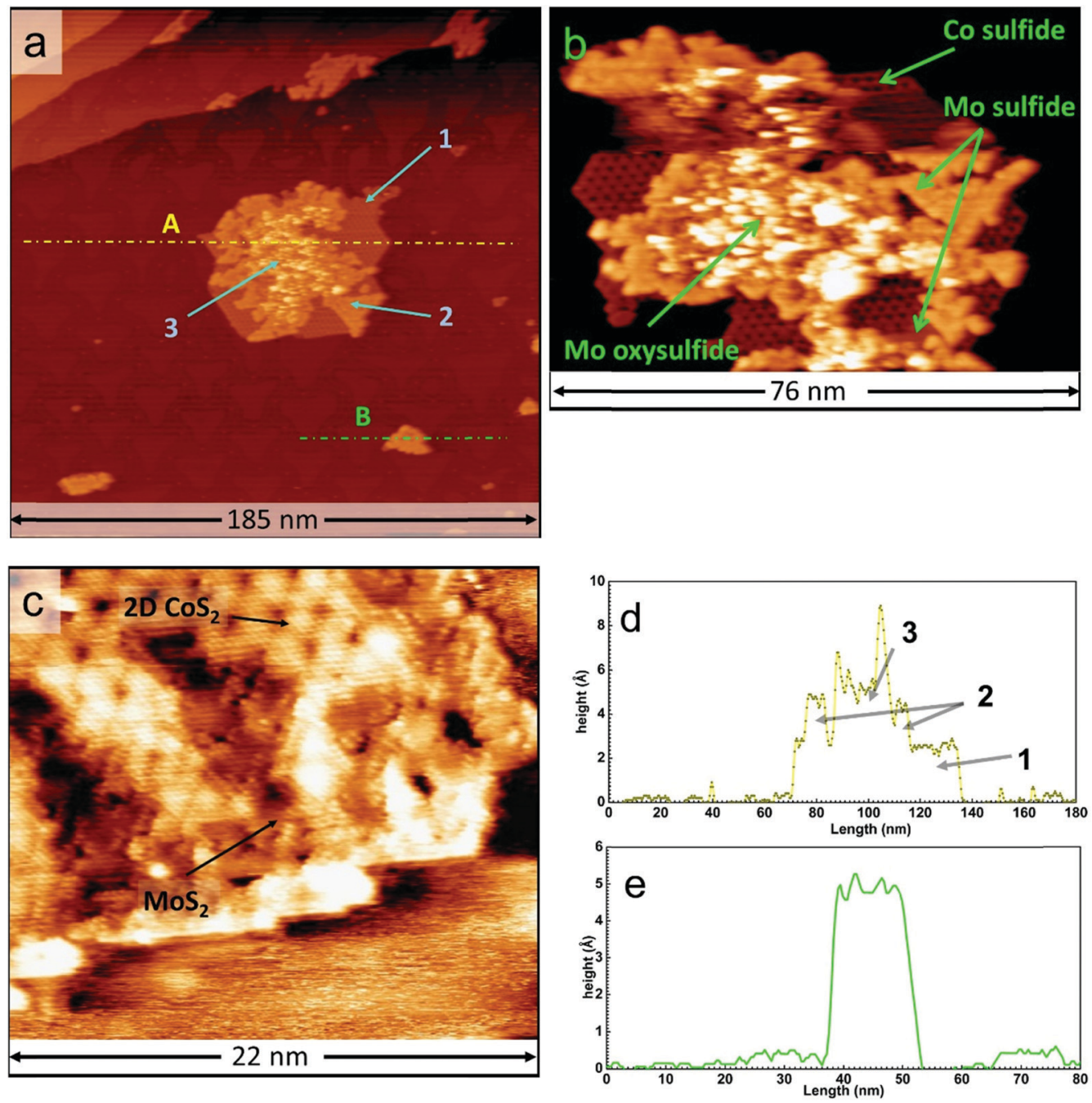

Fig. 3 (a) Large-scale STM image of the simultaneously sulfided Co and Mo oxides on the Au(111) substrate. Phase 1, 2 and 3 are marked in the figure. (b) Zoom-in of a large cluster containing the three phases. The $\mathrm{MoS}_{2}, 2 \mathrm{D} \mathrm{CoS}$, and the partially sulfided Mo oxide phases are marked. (c) Atom-resolved STM image of the defective $\mathrm{MoS}_{2}$ phase in one of the large clusters. ( $d$ and e) Measured height along the dashed lines marked A and B respectively in (Fig. 3a). The respective layers in (Fig. 3a) and (Fig. 3c) have been marked as (1) 2D cobalt sulfide, (2) MoS 2 slabs, and (3) partially sulfided Mo oxide. All STM images in (Fig. 3) were acquired at sample voltage $=-1.2 \mathrm{~V}$ and tunneling current $=200 \mathrm{pA}$.

to readily undergo O-S exchange even in vacuum pressures of $\mathrm{H}_{2} \mathrm{~S}^{28,60}$ Therefore, it is unlikely that any of the pure Mo oxides survive the annealing step in the presence of hydrogen sulfide. Furthermore, prior experiments involving the sulfidation of Mo oxides supported on gold have shown that an intermediate oxysulfide phase can form depending on the nature of the oxide precursor. ${ }^{28}$

Thus, the sulfidation carried out at $650 \mathrm{~K}$ for $25 \mathrm{~min}$ resulted in a partial conversion of the oxide phase and the formation of highly defective $\mathrm{MoS}_{2}$ slabs. We devised two strategies to enhance the yield of the Mo and Co sulfide phase. For this, identical precursors of mixed Mo and Co oxide nanoparticles as in Fig. 2a were prepared. In the first strategy, we increased the time of sulfidation systematically to up to $90 \mathrm{~min}$. In the second method, we increased the sulfidation temperature to $730 \mathrm{~K}$ while maintaining the time of sulfidation to $25 \mathrm{~min}$. XPS was used to check for the completeness of the sulfidation process and STM images were acquired thereafter.
Fig. $4 \mathrm{a}$ and $\mathrm{b}$ show the Co $2 \mathrm{p}_{3 / 2}$ and Mo $3 \mathrm{~d}$ XPS spectra respectively, which were acquired for the samples (1) after the initial synthesis of Co oxide slabs supported on $\mathrm{Au}(111)$, (2) deposition of Mo oxide on the sample containing Co oxide supported on $\mathrm{Au}(111)$, and (3) after $25 \mathrm{~min}$ of sulfidation at $650 \mathrm{~K}$, (4) $50 \mathrm{~min}$ of sulfidation at $650 \mathrm{~K}$, (5) $90 \mathrm{~min}$ of sulfidation at $650 \mathrm{~K}$, and (6) $25 \mathrm{~min}$ of sulfidation at $730 \mathrm{~K}$. The Co $2 p_{3 / 2}$ spectrum (Fig. $4 a$ ) of the initially grown Co oxide slabs on $\mathrm{Au}(111)$ consists of contributions of a high-spin Co oxide and a Co metal component. The Co oxide component shows a broad main peak at $780 \mathrm{eV}$ with shoulders at 782 and $785.4 \mathrm{eV}$. Furthermore, a broad satellite feature at $786.4 \mathrm{eV}$ is also detected. These observations are in agreement with prior experimental reports of -Co-O-type Co oxide slabs supported on $\mathrm{Au}(111)^{42}$ and in line with our interpretation of the STM image in Fig. 1a. The Co metal component has a main peak at $778.2 \mathrm{eV}$ and two satellites at 781.2 and $783.2 \mathrm{eV}$. This Co metal 

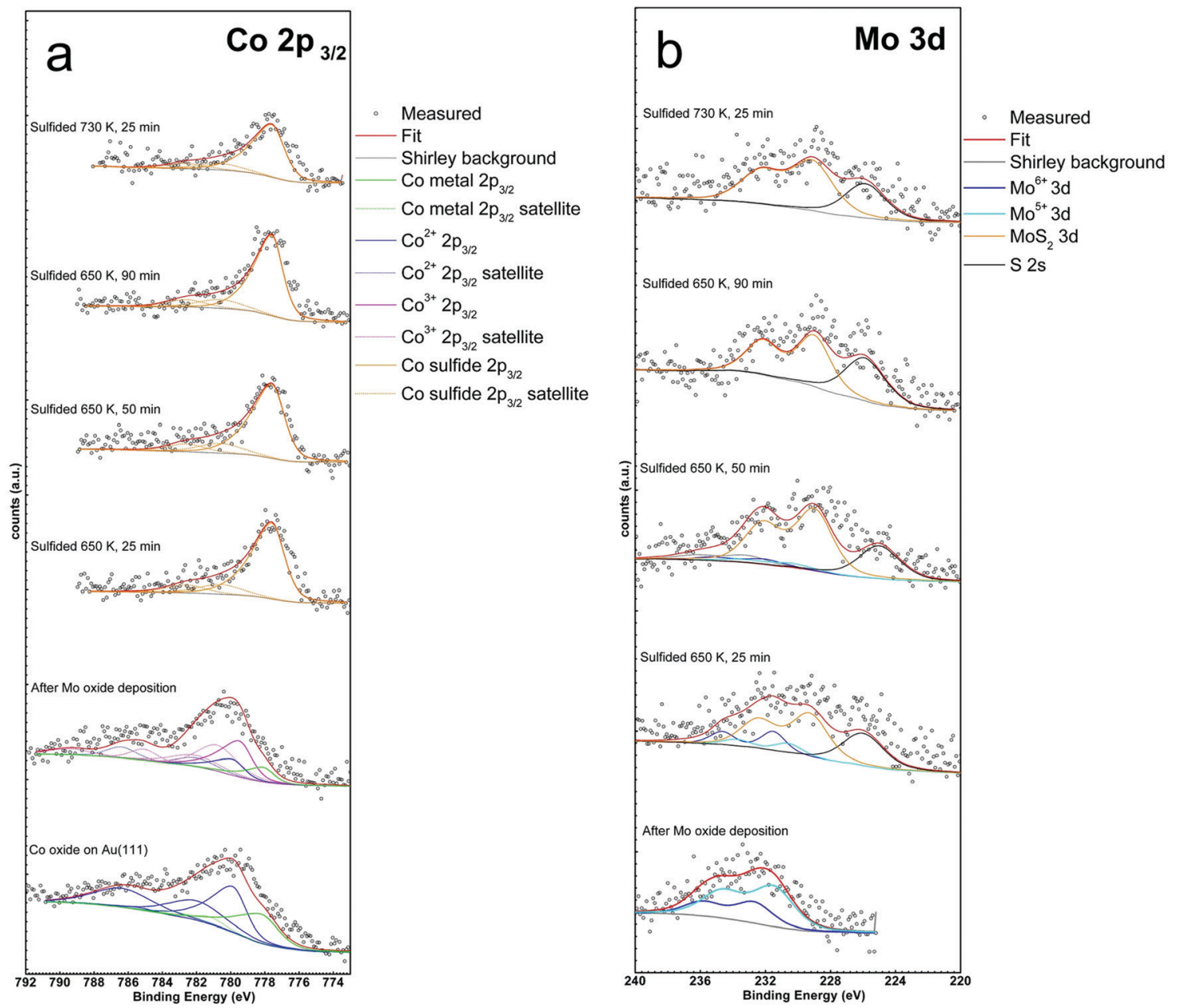

Fig. 4 (a and b) XPS spectra of Co $2 p_{3 / 2}$ and Mo 3d regions respectively at various stages of oxide precursor synthesis and subsequent sulfidation.

component is very likely from Co that is alloyed with gold and is present in the sub-surface region. After the deposition of Mo oxide, the main peak of the Co $2 \mathrm{p}_{3 / 2}$ spectrum shows a $0.5 \mathrm{eV}$ shift towards higher binding energy at $780.6 \mathrm{eV}$ (see Fig. 4a). Peak fitting shows contributions from $\mathrm{Co}^{3+}$ oxide, $\mathrm{Co}^{2+}$ oxide as well as a minor contribution from Co metal. Fig. 4a shows that the contribution from the $\mathrm{Co}^{2+}$ oxide and the Co metal component decreases significantly after Mo deposition while the $\mathrm{Co}^{3+}$ component is dominant which suggests oxidation of some of the $\mathrm{Co}^{2+}$ to $\mathrm{Co}^{3+}$. This supports our observations from the STM images in Fig. 2a which suggest a partial oxidation of the $\mathrm{Co}^{2+}$ slabs into slabs containing $\mathrm{Co}^{3+}$ oxides. Similar observations were also reported in the work of Fester et al. ${ }^{42,43}$ We note that the presence of $\mathrm{CoOOH}$ in the Co oxide slabs cannot be ruled out as its reference spectrum also has similar features to those of $\mathrm{Co}^{3+}$ oxide. $^{55}$

The $\mathrm{Mo}_{3 \mathrm{~d}}$ spectrum of the Mo oxide deposited on the sample containing Co oxide slabs supported on Au(111) (Fig. 4b) shows the presence of predominantly $\mathrm{Mo}^{6+}$ and $\mathrm{Mo}^{5+}$ oxidation states. $^{24,28}$ The higher local pressure of oxygen attained with the usage of a doser ensures that extensive thermal reduction of Mo oxides as in the work of Salazar et $a l^{28}$ is greatly suppressed.
Upon sulfidation for all the conditions used, the Co $2 \mathrm{p}_{3 / 2}$ main peak shifts to lower binding energy at $777.9 \mathrm{eV}$, indicating a conversion to the sulfide. Its satellite feature also shifts to $782.6 \mathrm{eV}$ and is consistent with the reference spectra of $2 \mathrm{D}$ cobalt sulfide on $\mathrm{Au}(111)^{59}$ and other supports. ${ }^{24}$ Components from the $\mathrm{Co}^{2+}$ and $\mathrm{Co}^{3+}$ oxide were not observed for all the sulfided samples. This suggests that the sulfidation is complete already within the first $25 \mathrm{~min}$ at $650 \mathrm{~K}$. This is also in agreement with our observation of a pristine $2 \mathrm{D} \mathrm{CoS}_{2}$ phase in the STM images (phase 1, Fig. 3a). The Mo 3d spectrum, on the other hand, shows a progressive shift to the $\mathrm{Mo}^{4+}$ oxidation state with increasing sulfidation time. Additionally, a component at $226 \mathrm{eV}$ belonging to the $\mathrm{S} 2 \mathrm{~s}$ signal is also detected. The $\mathrm{Mo}^{4+}$ and the S 2s features are attributed to the formation of $\mathrm{MoS}_{2}$. The $\mathrm{S}$ 2s also likely has some contribution from sulfur adsorbed on $\mathrm{Au}(111)$ due to $\mathrm{H}_{2} \mathrm{~S}$ exposure. Some contributions from the $\mathrm{Mo}^{5+}$ and $\mathrm{Mo}^{6+}$ components are also detected. These components are attributed to Mo oxide phases that are not completely sulfided (phase 3, Fig. 3a) and likely are present as an oxysulfide. Furthermore, it is also possible that some of the $\mathrm{Mo}^{4+}$ component arises due to incomplete sulfidation and reduction of Mo oxide in the presence of $\mathrm{H}_{2} \mathrm{~S}$. After $90 \mathrm{~min}$ of 
Table 2 Ratio and coverage of Co and Mo determined from the XPS spectra in Fig. 4

\begin{tabular}{llll}
\hline & Co:Mo ratio & $\begin{array}{l}\text { Co coverage }^{a} \\
\text { (ML) }\end{array}$ & $\begin{array}{l}\text { Mo coverage } \\
\text { (ML) }\end{array}$ \\
\hline Co oxide/Au(111) & & 0.061 & \\
Mo oxide + Co oxide & 0.98 & 0.055 & 0.056 \\
Sulfidation 650 K 25 min & 1.05 & 0.061 & 0.058 \\
Sulfidation 650 K 50 min & 1.02 & 0.062 & 0.061 \\
Sulfidation 650 K 90 min & 1.04 & 0.059 & 0.057 \\
Sulfidation 730 K 25 min & 0.83 & 0.042 & 0.050 \\
${ }^{a}$ With respect to Au(111), ML = monolayers. \\
\hline
\end{tabular}

sulfidation, the Mo 3d spectrum shows only an $\mathrm{Mo}^{4+}$ component characteristic of pristine $\mathrm{MoS}_{2}{ }^{28}$ indicating complete sulfidation of Mo. However, traces of the incompletely sulfided phase were observed in the STM images obtained after 90 min of sulfidation at $650 \mathrm{~K}$ (see ESI, $\dagger$ Fig. S4). This is expected as the STM has a much lower detection limit than the XPS. After sulfidation at $730 \mathrm{~K}$ for $25 \mathrm{~min}$, the Mo 3d spectrum shows only the $\mathrm{Mo}^{4+}$ and $\mathrm{S} 2 \mathrm{~s}$ features characteristic of $\mathrm{MoS}_{2}$ suggesting a complete conversion to $\mathrm{MoS}_{2}$. For the corresponding $\mathrm{O}$ 1s and S 2p spectra, we refer to the ESI, $\dagger$ Fig. S5.

We note that due to our aim of synthesizing small nanoclusters of the Co-promoted $\mathrm{MoS}_{2}$ phase for catalytic studies, low coverages of Mo and Co are used in the experiments presented in this study. Therefore, it is only expected that the signal-to-noise ratio in the XPS data is low because of which there is greater uncertainty in the peak fitting used. However, due to the significant morphological changes occurring during the sulfidation process, it is important to obtain chemical information of our samples to gain more insights. Given the chemically blind nature of the STM and its inability to quantitatively probe the sub-surface, information on the coverages of Co and Mo obtained from the XPS data is still useful due to its ability to simultaneously probe the surface and the sub-surface atomic layers.

The Co: Mo ratio and the coverages of the Co and Mo were estimated from the XPS spectra by taking into account the relative sensitivity factors of Co and Mo (see Table 2). The oxidic precursor containing the Co oxide slabs has a measured Co coverage of 0.061 ML. After the deposition of Mo oxide
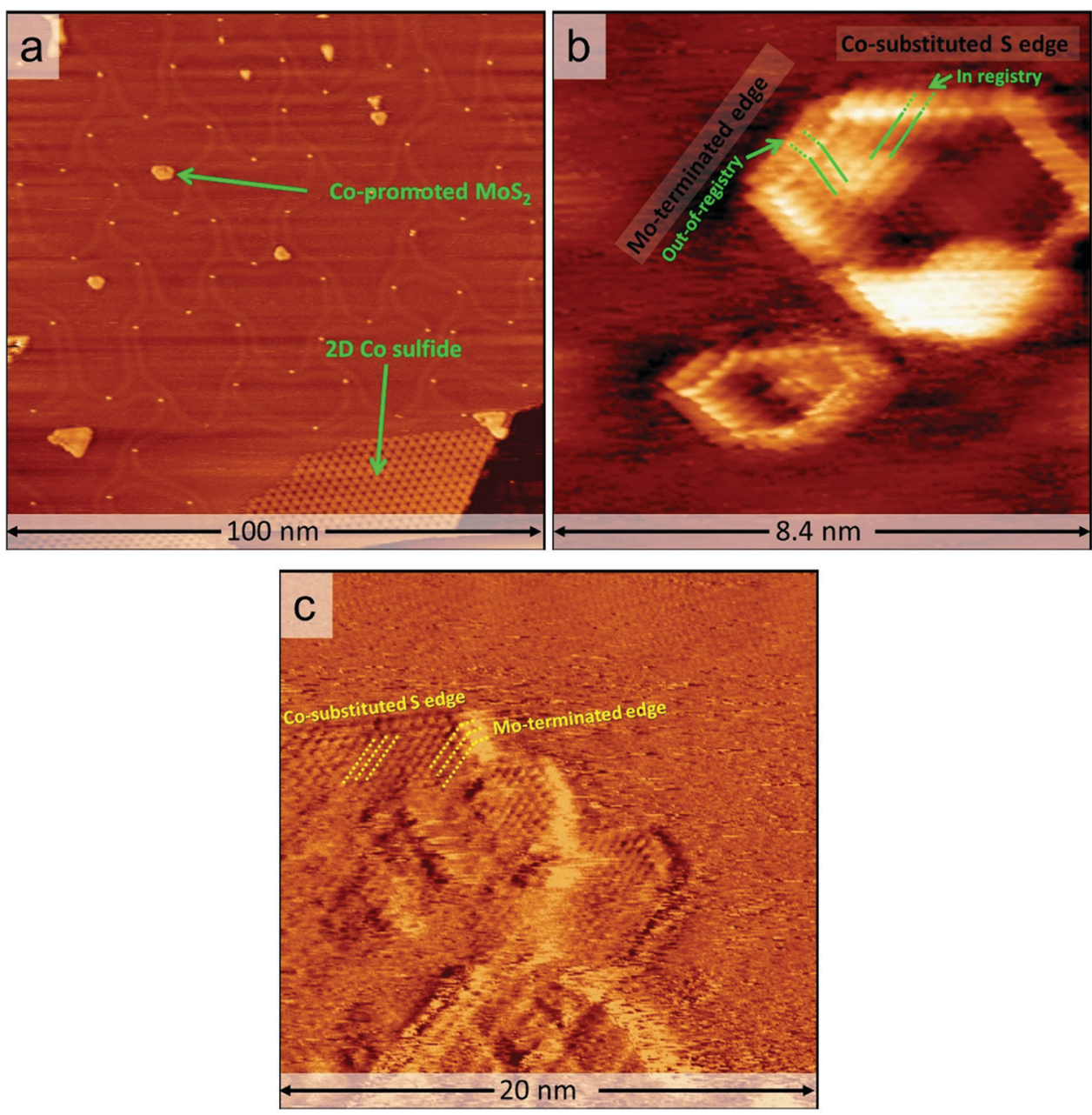

Fig. 5 (a) Large-scale STM image showing truncated hexagonal $\mathrm{MoS}_{2}$ slabs formed because of Co incorporation into the $\mathrm{S}$ edge, sample voltage $=-1 \mathrm{~V}$, tunneling current $=150 \mathrm{pA}$. (b) Atom-resolved STM image of hexagonal Co-promoted MoS 2 slabs showing the Mo-terminated and the Co-substituted $\mathrm{S}$ edges, sample voltage $=-0.5 \mathrm{~V}$, tunneling current $=200 \mathrm{pA}$. (c) Atom-resolved STM image of the $\mathrm{MoS}_{2}$ slabs in the large clusters, sample voltage $=-0.35 \mathrm{~V}$, tunneling current $=900 \mathrm{pA}$. 
nanoparticles with a coverage of $0.056 \mathrm{ML}$, the coverage of Co decreases to $0.055 \mathrm{ML}$. We attribute this decrease to attenuation of the XPS signal of Co due to the Mo oxide growing over some of the Co oxide slabs. After sulfidation for $25 \mathrm{~min}$ at $650 \mathrm{~K}$, we observe that the Co coverage is restored to the initial value of $0.061 \mathrm{ML}$ while the Mo coverage only increases marginally resulting in a Co:Mo ratio of $1.05: 1$. This is a direct consequence of the morphological changes observed in the STM images wherein both the Co and Mo oxides sulfide and spread on the surface to form large 2D clusters. The Co:Mo ratio as well as the coverages of Mo and Co remain constant with increasing time of sulfidation within the limits of the minute differences between the initial precursors prepared for each of the sulfidation experiments and the inherent uncertainty due to the low signal-to-noise ratio in the XPS data. After sulfidation at $730 \mathrm{~K}$ for $25 \mathrm{~min}$, however, we observe a significant decrease in the Co:Mo ratio as well as a decrease in the coverages of Co and Mo. We attribute this change to the increased tendency of Co and Mo to alloy with Au at $730 \mathrm{~K}$ due to the surface of $\mathrm{Au}(111)$ being more sulfur-deficient than at $650 \mathrm{~K}$. This leads to partial lifting of the herringbone reconstruction and formation of vacancy islands on the Au surface (see ESI, $\dagger$ Fig. S4b).

In all of the sulfided samples studied in this work, individual single-layer (SL) slabs with a truncated hexagonal shape were also observed to form (Fig. 5a). We identify these slabs as the Copromoted $\mathrm{MoS}_{2}$ slabs. It is also known that $\mathrm{MoS}_{2}$ slabs without the Co-promoter atoms adopt a fully triangular shape under sulfur-rich conditions as used in this study. This is because the Mo-terminated edge is thermodynamically more favorable than an S-terminated edge for a pristine $\mathrm{MoS}_{2}$ slab. ${ }^{49}$ Incorporation of Co atoms into the $\mathrm{S}$ edge leads to thermodynamic stability and hence, the Co-promoted $\mathrm{MoS}_{2}$ slabs adopt a hexagonal or truncated hexagonal shape displaying both the Mo- and S-terminated edges (see ESI, $\dagger$ Fig. S6). Thus, the formation of hexagonal slabs under the sulfur-rich conditions used in our study is a signature of Co being incorporated into the edges of the $\mathrm{MoS}_{2}$ slabs. ${ }^{49}$ Fig. 5b shows the zoom-in of a Co-promoted $\mathrm{MoS}_{2}$ slab. It is known from prior STM experiments on $\mathrm{MoS}_{2}$ that it is the sulfur atoms that are imaged as bright protrusions in the basal plane at the sample voltages used in our experiment. ${ }^{9}$ In Fig. 5b, we observe that the penultimate row of protrusions along the edges of the Co-promoted $\mathrm{MoS}_{2}$ slabs appears brighter than those in the basal plane. This feature is attributed to the electronic effects due to 1D metallic states called as BRIM sites present on the edge sulfur atoms. ${ }^{9,49}$ In the past, a combination of STM experiments and DFT calculations has been used to show that the registry of the ultimate row of protrusions along the edges of a Co-promoted $\mathrm{MoS}_{2}$ slabs with respect to the basal plane can be used to identify the type and the sulfur saturation of the edges. ${ }^{49}$ In Fig. $5 \mathrm{~b}$, the rows of atoms in the basal plane have been marked with green lines as a guide for the eyes. We observe that along one of the edges, the bright protrusions are in registry with the basal plane protrusions. This is the signature of a $100 \%$ sulfur-saturated Co-substituted S edge. ${ }^{49}$ On the adjacent edge, however, the edge protrusions are clearly out of registry with respect to the line of protrusions in the basal plane. This edge is identified as the $100 \%$ sulfur-saturated
Mo-terminated edge in line with the work of Grønborg et al. ${ }^{49}$ Fig. 5c shows an atom-resolved STM image of a large cluster containing the $\mathrm{MoS}_{2}$ and the 2D CoS 2 phase, measured after sulfidation for 90 minutes at $650 \mathrm{~K}$. Based on the same technique of edge identification, we identify the presence of the Co-substituted S edge and the Mo-terminated edge in the $\mathrm{MoS}_{2}$ phase. This observation shows that the Co-substituted S edge is formed not only in the hexagonal SL Co-promoted $\mathrm{MoS}_{2}$ slabs, but also in the $\mathrm{MoS}_{2}$ phase present in the larger clusters.

\section{Discussion}

We have studied the process of growing a mixed Mo and Co oxide precursor and the subsequent transformation to Mo and Co sulfide through sulfidation with $\mathrm{H}_{2} \mathrm{~S}$. We have carried out the sulfidation at $650 \mathrm{~K}$ for 25 to up to 90 minutes and at $730 \mathrm{~K}$ for 25 minutes. Our objective has been to gain insights into the process of oxide-to-sulfide conversion to form the Co-promoted $\mathrm{MoS}_{2}$ phase.

Our results from XPS and STM studies show that there is a strong preference for the sulfidation of Co oxide. This is evident from the complete conversion of the Co oxide within the first 25 min of sulfidation. The sulfidation of Mo oxide on the other hand, is observed to be thermally activated. The sulfidation process is accompanied by a change in morphology from welldistributed nanoparticles and slabs to large clusters containing multiple phases. The formation of large clusters after the sulfidation process from a precursor containing oxide nanoparticles of Co and Mo can be driven by two factors, namely, the temperature and the presence of sulfur species. Annealing the oxidic precursor containing the Mo and Co oxides to $600 \mathrm{~K}$ in the absence of $\mathrm{H}_{2} \mathrm{~S}$ causes clustering of the Mo oxide phases (see ESI, $\dagger$ Fig. S7). This clustering is accompanied by reduction of the Mo oxide phase as can be seen in the Mo 3d spectra in Fig. $4 \mathrm{~b} . \mathrm{Mo}^{6+}$ oxide is known to undergo reduction to $\mathrm{Mo}^{5+}$ and $\mathrm{Mo}^{4+}$ states at temperatures above $600 \mathrm{~K}$ even in mild oxygen backgrounds. $^{28,31,58}$ This thermal reduction is typically accompanied by a tendency to form large atomically flat clusters due to a thermally activated cluster diffusion process. $^{29,31,58}$ The cobalt oxide slabs, on the other hand, are observed to be stable to such heat treatments up to $650 \mathrm{~K}$. However, in the presence of sulfur, diffusion of Co is known to be greatly enhanced due to the formation of Co-sulfur complexes even at $300 \mathrm{~K}$ on $\mathrm{Au}(111) .{ }^{61}$ Therefore, the observed morphological changes are very well in agreement with previous experimental reports.

Our STM experiments also show that the formation of the SL Co-promoted $\mathrm{MoS}_{2}$ slabs with truncated hexagonal shape is unaffected by the temperature or the duration of sulfidation as they are observed to form in all the sulfide samples studied in this work. Additionally, formation of the $\mathrm{MoS}_{2}$ phase in the large clusters with the Co-substituted $\mathrm{S}$ edge is not prevented by the slower sulfidation of Mo oxide. However, the yield of free SL Co-promoted $\mathrm{MoS}_{2}$ slabs is significantly less than what would be obtained if the respective metallic precursors were used as a 
starting point as in the recipes reported in literature. ${ }^{23}$ This is likely due to the tendency of the mixed oxide precursor to spread and form large clusters in the presence of sulfur and at elevated temperature, which then leads to differential sulfidation of the Co and Mo oxide phases in the cluster, thereby reducing the yield of Co-promoted $\mathrm{MoS}_{2}$ phase. Given that the Mo oxide phase that is not fully sulfided is encapsulated by the $2 \mathrm{D} \mathrm{CoS}$ and the $\mathrm{MoS}_{2}$ slabs as can be seen in the STM images presented in this work, it is possible that the sulfide sheets formed create additional barriers for sulfur atoms to diffuse to the partially converted Mo oxide phase. This is quite in contrast to the previously reported synthesis strategies that involve $\mathrm{Au}(111)$-supported metallic Co and Mo nanoparticles as the precursor wherein the nanoparticles readily sulfide simultaneously and form Co-promoted $\mathrm{MoS}_{2}$ slabs. ${ }^{23,49}$ Despite the low yield, we show that using a precursor with mixed Mo and Co oxides is a viable strategy to synthesize the Co-promoted $\mathrm{MoS}_{2}$ phase in order to carry out fundamental studies relevant for fields such as catalysis. One possible strategy to increase the yield of Co-promoted $\mathrm{MoS}_{2}$ could involve starting with a precursor containing other ratios of Mo and Co. Another solution may lie in the use of model supports like $\mathrm{TiO}_{2}(110)$ that interact more strongly than $\mathrm{Au}(111)$ with $\mathrm{Co}$ and Mo oxides, and thus, prevent large clusters from forming.

\section{Conclusions}

Starting with a mixture of Mo and Co oxide nanoparticles on $\mathrm{Au}(111)$, we have investigated the process of their sulfidation using STM and XPS. We have shown that it is possible to synthesize single-layer Co-promoted $\mathrm{MoS}_{2}$ slabs using this mixed oxide precursor independent of the temperature and duration of the sulfidation process. We have also shown that due to the tendency to reduce and spread on the surface, the Mo and Co oxides form large clusters that contain the $\mathrm{MoS}_{2}, 2 \mathrm{D}$ $\mathrm{CoS}_{2}$ and likely an incompletely sulfided Mo oxide phase depending on the temperature and duration of the sulfidation. The $\mathrm{MoS}_{2}$ in these large clusters also has a tendency to incorporate Co atoms in its $\mathrm{S}$ edges. Hence, we have shown that sulfiding a mixture of Co and Mo oxide nanoparticles is a feasible recipe to make Co-promoted $\mathrm{MoS}_{2}$ for fundamental catalysis studies, especially those for hydrodesulfurization.

\section{Conflicts of interest}

There are no conflicts to declare.

\section{References}

1 B. Liu, A. Abbas and C. Zhou, Adv. Electron. Mater., 2017, 3, 1700045.

2 M. A. Bissett, S. D. Worrall, I. A. Kinloch and R. A. W. Dryfe, Electrochim. Acta, 2016, 201, 30-37.

3 S. Manzeli, D. Ovchinnikov, D. Pasquier, O. V. Yazyev and A. Kis, Nat. Rev. Mater., 2017, 2, 17033.
4 D. Lembke, S. Bertolazzi and A. Kis, Acc. Chem. Res., 2015, 48, 100-110.

5 W. Yin, L. Yan, J. Yu, G. Tian, L. Zhou, X. Zheng, X. Zhang, Y. Yong, J. Li, Z. Gu and Y. Zhao, ACS Nano, 2014, 8, 6922-6933.

6 J. Feng, M. Graf, K. Liu, D. Ovchinnikov, D. Dumcenco, M. Heiranian, V. Nandigana, N. R. Aluru, A. Kis and A. Radenovic, Nature, 2016, 536, 197-200.

7 W. Wu, L. Wang, Y. Li, F. Zhang, L. Lin, S. Niu, D. Chenet, X. Zhang, Y. Hao, T. F. Heinz, J. Hone and Z. L. Wang, Nature, 2014, 514, 470-474.

8 Y. Li, Y. L. Li, C. M. Araujo, W. Luo and R. Ahuja, Catal. Sci. Technol., 2013, 3, 2214-2220.

9 S. Helveg, J. V. Lauritsen, E. Lægsgaard, I. Stensgaard, J. K. Nørskov, B. S. Clausen, H. Topsøe and F. Besenbacher, Phys. Rev. Lett., 2000, 84, 951-954.

10 S. S. Grønborg, S. Ulstrup, M. Bianchi, M. Dendzik, C. E. Sanders, J. V. Lauritsen, P. Hofmann and J. A. Miwa, Langmuir, 2015, 31, 9700-9706.

11 J. Kibsgaard, J. V. Lauritsen, E. Lægsgaard, B. S. Clausen, H. Topsøe and F. Besenbacher, J. Am. Chem. Soc., 2006, 128, 13950-13958.

12 H. Liu, Y. Li, M. Xiang, H. Zeng and X. Shao, ACS Nano, 2019, 13, 6083-6089.

13 R. P. Galhenage, H. Yan, T. B. Rawal, D. Le, A. J. Brandt, T. D. Maddumapatabandi, N. Nguyen, T. S. Rahman and D. A. Chen, J. Phys. Chem. C, 2019, 123, 7185-7201.

14 J. Kibsgaard, B. S. Clausen, H. Topsøe, E. Lægsgaard, J. V. Lauritsen and F. Besenbacher, J. Catal., 2009, 263, 98-103.

15 H. Topsøe, B. S. Clausen, R. Candia, C. Wivel and S. Mørup, J. Catal., 1981, 68, 433-452.

16 X. Dai, K. Du, Z. Li, M. Liu, Y. Ma, H. Sun, X. Zhang and Y. Yang, ACS Appl. Mater. Interfaces, 2015, 7, 27242-27253.

17 D. L. S. Nieskens, D. Ferrari, Y. Liu and R. Kolonko, Catal. Commun., 2011, 14, 111-113.

18 D. Escalera-López, Y. Niu, J. Yin, K. Cooke, N. V. Rees and R. E. Palmer, ACS Catal., 2016, 6, 6008-6017.

19 J. Deng, H. Li, J. Xiao, Y. Tu, D. Deng, H. Yang, H. Tian, J. Li, P. Ren and X. Bao, Energy Environ. Sci., 2015, 8, 1594-1601.

20 Y. Okamoto, Catal. Today, 2008, 132, 9-17.

21 M. J. Menart, J. E. Hensley and K. E. Costelow, Appl. Catal., A, 2012, 437-438, 36-43.

22 L. S. Byskov, J. K. Nørskov, B. S. Clausen and H. Topsøe, Catal. Lett., 2000, 64, 95-99.

23 J. V. Lauritsen, J. Kibsgaard, G. H. Olesen, P. G. Moses, B. Hinnemann, S. Helveg, J. K. Nørskov, B. S. Clausen, H. Topsøe, E. Lægsgaard and F. Besenbacher, J. Catal., 2007, 249, 220-233.

24 R. G. Leliveld, A. J. Van Dillen, J. W. Geus and D. C. Koningsberger, J. Catal., 1997, 171, 115-129.

25 W. Qian, A. Ishihara, Y. Aoyama and T. Kabe, Appl. Catal., A, 2000, 196, 103-110.

26 M. Kobayashi and M. Flytzani-Stephanopoulos, Ind. Eng. Chem. Res., 2002, 41, 3115-3123.

27 C. J. Chen and R. K. Chiang, Dalton Trans., 2011, 40, 880-885. 
28 N. Salazar, I. Beinik and J. V. Lauritsen, Phys. Chem. Chem. Phys., 2017, 19, 14020-14029.

29 S. Guimond, D. Göbke, J. M. Sturm, Y. Romanyshyn, H. Kuhlenbeck, M. Cavalleri and H. J. Freund, J. Phys. Chem. C, 2013, 117, 8746-8757.

30 M. M. Biener and C. M. Friend, Surf. Sci., 2004, 559, 173-179.

31 Z. Song, T. Cai, Z. Chang, G. Liu, J. A. Rodriguez and J. Hrbek, J. Am. Chem. Soc., 2003, 125, 8059-8066.

32 M. M. Biener, J. Biener, R. Schalek and C. M. Friend, J. Chem. Phys., 2004, 121, 12010-12016.

33 H. Uetsuka, H. Onishi, S. Ikeda, Y. Harada, H. Sakama and Y. Sakashita, e-J. Surf. Sci. Nanotechnol., 2003, 1, 80-83.

34 R. V. Mom, M. J. Rost, J. W. M. Frenken and I. M. N. Groot, J. Phys. Chem. C, 2016, 120, 19737-19743.

35 J. Haber, P. Nowak and J. Stoch, Bull. Polish Acad. Sci. Chem., 1997, 45, 139-149.

36 J. Fester, M. Bajdich, A. S. Walton, Z. Sun, P. N. Plessow, A. Vojvodic and J. V. Lauritsen, Top. Catal., 2017, 60, 503-512.

37 M. De Santis, A. Buchsbaum, P. Varga and M. Schmid, Phys. Rev. B: Condens. Matter Mater. Phys., 2011, 84, 125430.

38 S. Entani, M. Kiguchi and K. Saiki, Surf. Sci., 2004, 566-568, 165-169.

39 I. Sebastian, M. Heiler, K. Meinel and H. Neddermeyer, Appl. Phys. A: Mater. Sci. Process., 1998, 66, 525-528.

40 M. Li and E. I. Altman, J. Phys. Chem. C, 2014, 118, 12706-12716.

41 M. Li and E. I. Altman, Surf. Sci., 2014, 619, 6-10.

42 J. Fester, Z. Sun, J. Rodríguez-Fernández, A. Walton and J. V. Lauritsen, J. Phys. Chem. B, 2018, 122, 561-571.

43 J. Fester, A. Walton, Z. Li and J. V. Lauritsen, Phys. Chem. Chem. Phys., 2017, 19, 2425-2433.

44 A. S. Walton, J. Fester, M. Bajdich, M. A. Arman, J. Osiecki, J. Knudsen, A. Vojvodic and J. V. Lauritsen, ACS Nano, 2015, 9, 2445-2453.

45 J. Bin Chung and J. S. Chung, Chem. Eng. Sci., 2005, 60, 1515-1523.

46 A. F. H. Sanders, A. M. De Jong, V. H. J. De Beer, J. A. R. Van Veen and J. W. Niemantsverdriet, Appl. Surf. Sci., 1999, 144145, 380-384.

47 L. Coulier, V. H. J. De Beer, J. A. R. Van Veen and J. W. Niemantsverdriet, Top. Catal., 2000, 13, 99-108.
48 R. G. Leliveld, A. J. Van Dillen, J. W. Geus and D. C. Koningsberger, J. Catal., 1997, 165, 184-196.

49 S. S. Grønborg, N. Salazar, A. Bruix, J. Rodríguez-Fernández, S. D. Thomsen, B. Hammer and J. V. Lauritsen, Nat. Commun., 2018, 9, 1-11.

50 C. T. Herbschleb, P. C. Van Der Tuijn, S. B. Roobol, V. Navarro, J. W. Bakker, Q. Liu, D. Stoltz, M. E. CañasVentura, G. Verdoes, M. A. Van Spronsen, M. Bergman, L. Crama, I. Taminiau, A. Ofitserov, G. J. C. Van Baarle and J. W. M. Frenken, Rev. Sci. Instrum., 2014, 85, 83703.

51 M. J. Rost, L. Crama, P. Schakel, E. Van Tol, G. B. E. M. Van Velzen-Williams, C. F. Overgauw, H. Ter Horst, H. Dekker, B. Okhuijsen, M. Seynen, A. Vijftigschild, P. Han, A. J. Katan, K. Schoots, R. Schumm, W. Van Loo, T. H. Oosterkamp and J. W. M. Frenken, Rev. Sci. Instrum., 2005, 76, 053710.

52 M. J. Rost, G. J. C. van Baarle, A. J. Katan, W. M. van Spengen, P. Schakel, W. A. van Loo, T. H. Oosterkamp and J. W. M. Frenken, Asian J. Control, 2009, 11, 110-129.

53 I. Horcas, R. Fernández, J. M. Gómez-Rodríguez, J. Colchero, J. Gómez-Herrero and A. M. Baro, Rev. Sci. Instrum., 2007, 78, 013705.

54 C. D. Wagner, J. Electron Spectrosc. Relat. Phenom., 1983, 32, 99-102.

55 M. C. Biesinger, B. P. Payne, A. P. Grosvenor, L. W. M. Lau, A. R. Gerson and R. S. C. Smart, Appl. Surf. Sci., 2011, 257, 2717-2730.

56 L. van Haandel, G. Smolentsev, J. A. van Bokhoven, E. J. M. Hensen and T. Weber, ACS Catal., 2020, 10, 10978-10988.

57 G. M. Bremmer, L. van Haandel, E. J. M. Hensen, J. W. M. Frenken and P. J. Kooyman, Appl. Catal., B, 2019, 243, 145-150.

58 X. Deng, S. Y. Quek, M. M. Biener, J. Biener, D. H. Kang, R. Schalek, E. Kaxiras and C. M. Friend, Surf. Sci., 2008, 602, 1166-1174.

59 M. K. Prabhu, D. Boden, M. J. Rost, J. Meyer and I. M. N. Groot, J. Phys. Chem. Lett., 2020, 11, 9038-9044.

60 E. L. D. Hebenstreit, W. Hebenstreit and U. Diebold, Surf. Sci., 2000, 461, 87-97.

61 J. Kibsgaard, K. Morgenstern, E. Lægsgaard, J. V. Lauritsen and F. Besenbacher, Phys. Rev. Lett., 2008, 100, 116104. 